\title{
A PROTEÇÃO JURÍDICA DOS PORTADORES DE NECESSIDADES EDUCACIONAIS ESPECIAIS NO BRASIL
}

Elisandra Alice dos Santos

Advogada

Graduada pela Faculdade de Direito de Franca

Especialista em Direito Público pela Universidade Potiguar

Ex-bolsista da FAPESP

eli_alice@hotmail.com

RESUMO: O trabalho inicialmente individualiza os portadores de necessidades educacionais especiais e traça a evolução de sua educação no Brasil. Em seqüência, busca-se compilar os principais documentos internacionais, como a Declaração Mundial sobre Educação para Todos e a Declaração de Salamanca, referentes ao assunto, ressaltando suas prioridades. Sendo a inclusão educativa uma dessas prioridades, o trabalho visa demonstrar se a legislação brasileira visa implementá-la no mesmo sentido que o mundo. Por fim, aprofunda-se o tema na Constituição Federal para verificar qual o tratamento dado por ela àqueles que necessitam de uma Educação Especial e quais as conseqüências do não-oferecimento ou oferecimento inadequado de tal serviço por parte do Estado.

Palavras-chaves: portadores de necessidades educacionais especiais; Declaração Mundial de Educação para Todos; Declaração de Salamanca; educação na Constituição Federal; responsabilização do Estado.

\section{Title: The Legal Protection Of Educational Disabled People In Brazil}

ABSTRACT: Initially, this work individualizes the educational disabled people and plots the evolution of their education in Brazil. In sequence, it compiles and highlights the priorities of the most important international documents related to the subject like the "World Declaration on Education for All" and the "Salamanca Declaration". Being the educational inclusion one of the priorities, this work has the goal of demonstrating if Brazilian laws also aims at implementing this inclusion as the rest of the world. Finally, it develops deeply in the study of the Federal Constitution to verify which treatment it gives to the ones in need of Special Education and what the consequences of the no offer or inadequate offer of this service by the Estate are.

Key-words: disabled educational people; World Declaration on Education for All; Salamanca Declaration; education in the Federal Constitution; responsibleness of the Estate. 


\section{INTRODUÇÃO}

Ao longo dos séculos, são muitos os comportamentos e costumes aflorados da sociedade e do Estado. Alguns deles podem ser materializados de forma negativa, por exemplo, como a condição intrínseca de o ser humano criar relações de "superiorinferioridade" entre o grupo. Desse modo, geram-se valores de exaltação ou exclusão dos indivíduos.

Os mais diversificados valores incorporados pelo homem modificam-se de acordo com a cultura, grau de evolução de seu povo e contexto histórico no qual estão inseridos. Porém, há alguns que representam situação endêmica em grande parte do mundo. Em termos antropológicos, ser "criança", ser "mulher", ser "velho" ou ser "deficiente" representaram, em vários períodos da história, e representam ainda hoje, uma condição de marginalização, subalternidade de direitos e de funções sociais. No curso da pesquisa científica, o "ser deficiente" e sua "condição subalterna" serão focos de análises aprofundadas.

Perceptíveis são as inúmeras dificuldades de inclusão dos portadores de necessidades especiais no curso da história: desde a seleção natural, para além da seleção biológica dos espartanos, até a segregação operada pelos "esconjuradores" da Idade Média. Entretanto, com os estudos científicos sobre deficiência, realizados no século XIX e, depois, com a psicanálise freudiana, observou-se uma contribuição à compreensão e à educação dessas pessoas.

Em uma constante evolução, nota-se, hoje, em todo o mundo, uma política de criação de normas, planos de governo nas mais diversas áreas sociais e maior conscientização da sociedade, porém o quadro das pessoas portadoras de necessidades especiais está longe do ideal. O objetivo do trabalho será aclarar esse quadro, priorizando sua relação com o Direito, a Educação e o Estado, abordando, assim, suas principais problemáticas.

O papel do Estado brasileiro, no que diz respeito à educação especial, é de gerar e manter uma educação de qualidade aos educandos com necessidades especiais, de promover sua progressiva inclusão nas classes regulares, além de financiar todas as mudanças necessárias a esse fim - graduação de professores em Educação Especial, transformações no espaço físico, campanhas de conscientização para evitar o preconceito, etc.

Não sendo cumprido esse papel como deveria, verifica-se que a melhor Educação Especial encontrada no Brasil advém das instituições filantrópicas, que se mantêm com recursos de doações e até financiamento do próprio governo. 
Assim, qual o grau de responsabilidade que o Estado assume hoje perante a Educação Especial? Como o Poder Legislativo a concebe? Será que as normas brasileiras estão de acordo com a política mundial de inclusão?

O tema será abordado e explorado utilizando-se conjuntamente método de pesquisa teórico-dedutivo e o método documental, partindo de princípios gerais para se chegar a uma compreensão particular, via história e documentos atuais; e o sistema de organização lógica de idéias para a conclusão da pesquisa jurídica.

\section{1- DAS PESSOAS PORTADORAS DE NECESSIDADES EDUCACIONAIS ESPECIAIS}

\subsection{Caracterização}

Como todo estudo mais aprofundado, deve-se, primeiro, analisar conceitualmente seu objeto, evitando-se assim concepções errôneas ou superficiais. No caso em tela, as "pessoas especiais” são o objeto central sobre o qual serão tecidas considerações sociológicas, pedagógicas e jurídicas.

Uma primeira idéia que surge ao se enfocar esse tema é noção de "anormalidade” e “normalidade”. Pensamentos pré-concebidos levam à conclusão de que os "normais” são aqueles que não apresentam problemas no desenvolvimento escolar e social; e "anormais" os que, de alguma forma, os apresentam e não têm um rendimento esperado, ou seja, fora dos limites da normalidade. Então, de primeiro momento, vêem-se as pessoas com necessidades especiais como anormais.

Para DURKHEIN, os normais de uma espécie “... encontram-se se não em todos os indivíduos, pelo menos na maior parte deles e apresentam variações de um sujeito para outro compreendidas entre limites muito próximos.” Já os anormais, “... além de surgirem apenas em minorias, muitas vezes não chegam a durar a vida inteira dos indivíduos.” 1

No conceito de CANGUILHEM, normal é um fenômeno freqüente, ao passo que "uma norma só é a possibilidade de uma referência quando foi instituída ou escolhida como expressão de uma preferência e como instrumento de uma vontade de substituir um estado de coisas insatisfatório por um estado de coisas satisfatório”. ${ }^{2}$

\footnotetext{
${ }^{1}$ DURKHEIN, Émile. As regras do método sociológico. 2. ed. São Paulo: Abril Cultural, 1983. p. 114.

${ }^{2}$ CANGUILHEM, Georges. O normal e o patológico. 2. ed. Rio de Janeiro: Forense - Universitária, 1982. p. 212
} 
O anormal seria quem tivesse peculiaridades que se diferenciassem dos "traços comuns à grande maioria dos indivíduos que compõem uma espécie”. E acrescenta “Quando se fala em anomalias, não se pensa nas simples variações que são apenas desvios estatísticos, mas nas deformidades nocivas ou mesmo incompatíveis com a vida, ao nos referirmos à forma viva ou ao comportamento do ser vivo, não como fato estatístico mas a um tipo normativo de vida." 3

Visto isso, encontra-se uma dificuldade para estabelecer o limite entre a normalidade e a anormalidade para que se possa declarar que determinado indivíduo é “especial” ou não.

O meio social cria mecanismos para classificar indivíduos, quer como normais quer como anormais. O que é normal em um dado contexto, pode não o ser em outro. A definição de normalidade e anormalidade é relativa e o próprio meio possibilita situações de normalidade e de anormalidade, estabelecendo e criando normas e regras que acabam sendo seguidas e preconizadas como verdadeiras pela sociedade. ${ }^{4}$

Com a indefinição, cada um, com seu juízo particular, determina, ou melhor, marginaliza as pessoas anormais. Ao invés de a sociedade ajudar a potencializar as diversas capacidades daqueles que se apresentam como anormais, fixa-se somente na anormalidade, os resumindo a ela. "A anormalidade é isolada de maneira que o indivíduo que a expressa seja somente esse fenômeno, como se tratasse de um momento, de um processo onde se implica o ambiente, a história, os valores, as relações e os processos sociais nos quais cada vida individual sempre se insere". 5

Outras formas pelas quais as "pessoas especiais” são reconhecidas são os termos excepcionalidade ou deficiência, ambos fundados no quadro patológico do indivíduo. Voltando para a área educacional, todos aqueles que, de alguma forma, têm deficiência aparente no aprendizado normal ou se apresentam como exceção à regra da maioria do alunado, são conhecidos, hoje, como portadores de necessidades educacionais especiais.

Na legislação nacional, ainda há esse conceito de pessoas portadoras de necessidades educacionais especiais como deficientes, ao mencionar, no Estatuto da Criança e do Adolescente, capítulo IV, art.54, inc.III, que “é dever do Estado assegurar à criança e ao adolescente atendimento educacional especializado aos portadores de deficiência,

\footnotetext{
${ }^{3}$ CANGUILHEM, Georges. Op. cit. p. 102 e 106, nota 2.

${ }^{4}$ DEL MASSO, M. C. S. Orientação para o trabalho: uma proposta de adaptação curricular para alunos com deficiência mental. Tese (doutorado)- Universidade de São Paulo. São Paulo, 2000. p. 128

${ }^{5}$ BASAGLIA, Franco. O homem no pelourinho. Revista Educação e Sociedade- CEDES. n 23 São Paulo: Cortez- Centro de estudos educação e sociedade, 1986. p. 85
} 
preferencialmente na rede regular de ensino”. ${ }^{6}$ Essa terminologia é a encontrada em nossa Carta Magna.

O termo deficiente, ou melhor, portador de deficiência, ainda é amplamente usado, pois, como já dito, por se tratar de denominação patológica, é o seguido pela área médica, fisioterápica, psicológica. Entretanto, no campo pedagógico e educacional, o conceito está cada vez mais abrangente.

Atualmente, o conceito mais usado é de "pessoas portadoras de necessidades educacionais especiais”. Nesse sentido, a Lei de Diretrizes e Bases da Educação (1996) e a Declaração de Salamanca (1994).

“Entende-se por educação especial, para os efeitos desta lei, a modalidade de educação escolar oferecida preferencialmente na rede regular de ensino, para educandos portadores de necessidade especiais." 7

A Declaração de Salamanca conceitua: “(...) o termo necessidades educacionais especiais refere-se a todas as crianças ou jovens cujas necessidades educacionais especiais se originam em função de deficiências ou dificuldades de aprendizagem”. E acrescenta “durante os últimos quinze ou vinte anos, tem se tornado claro que o conceito de necessidades educacionais especiais teve de ser ampliado para incluir todas as crianças que não estejam conseguindo se beneficiar com a escola, seja por que motivo for." 8

Desse modo, as pessoas com necessidades especiais são os deficientes, os com dificuldades temporárias ou permanentes nas escolas, os repetentes, os que vivem nas ruas, os desnutridos e pobres, as vítimas de guerra e conflitos armados, os que sofreram emocionalmente com a vida... Todos os que precisam de maior atenção para que possam conseguir um aproveitamento escolar bom e evolutivo.

Porém, como percebido, o conceito é demasiadamente amplo e, por essa razão, o objeto de estudo terá maior foco nas pessoas especiais “com deficiência”.

\footnotetext{
${ }^{6}$ BRASIL, Lei no 8069, de 13 de julho de 1990. Dispõe sobre o Estatuto da Criança e do Adolescente Disponível em: <http:// www.educacaoonline.pro.br>. Acesso em: 30 mar. 2004.

${ }^{7}$ BRASIL, Lei n ${ }^{\circ}$ 9394, de 20 de dezembro de 1996, art. 58. Estabelece as Diretrizes e Bases da Educação Nacional. Disponível em: <http:// www.educacaoonline.pro.br>. Acesso em: 30 mar. 2004.

${ }^{8}$ ONU. UNESCO. Declaração de Salamanca, entre 7 e 10 de junho de 1994. Sobre princípios, política e prática em educação especial. Disponível em: <http:// www.educacaoonline.pro.br>. Acesso em: 02 abr. 2004.
} 


\subsection{Evolução histórica no Brasil}

Conforme Mazotta (1996), Sassaki (1997) e Mantoan (1998), a história da educação de pessoas com necessidades especiais no Brasil teve três grandes períodos, caminhando da exclusão à inclusão.

O primeiro iniciou-se com a educação em instituições especializadas, correspondendo ao período de 1854 a 1956. Começou com a criação do Imperial Instituto dos Meninos Cegos, em 12 de setembro de 1854 (hoje, Instituto Benjamin Constant) e do Instituto dos SurdosMudos (hoje, Instituto Nacional de Educação dos Surdos - INES), no Rio de Janeiro. As criações foram por iniciativa do governo imperial, ou melhor, por pressão de figuras próximas ao poder, por meio da "política de favores”. Tanto é que se deterioraram em pouco tempo.

Durante o Império, além desses institutos, iniciou-se o tratamento de deficientes mentais, no Hospital Psiquiátrico da Bahia (hoje, Hospital Juliano Moreira), em 1874, além do ato de criação do pavilhão Bourneville, no Hospital D. Pedro II (séc. XX).

Esse período é caracterizado por iniciativas isoladas, oficiais e particulares, de caráter assistencial. Essas poucas iniciativas isoladas refletiam uma sociedade rural e escravocrata em que não era necessário esse tipo de mão de obra nem existia uma ideologia educacional. A ação do Estado, em quantidade pequena e focalizada em deficientes mentais, foi se sistematizando e se organizando por meio da normatização e da centralização do atendimento por parte de órgãos públicos.

O segundo período vai de 1957 a 1993 e é definido por campanhas e ações nacionais. “Em 1961, com a homologação da Lei de Diretrizes e Bases 4024/61, a educação da pessoa

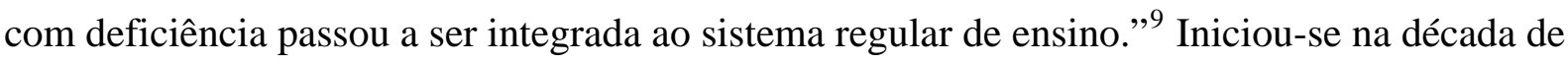
70, o movimento efetivo de integração social, o que implicava a adaptação dos portadores de necessidades especiais ao sistema escolar

Após a $2^{\mathrm{a}}$ Guerra Mundial houve maior preocupação com os deficientes, começou-se a acreditar no potencial dessas pessoas. A educação especial pública ampliou-se, principalmente, na década de 70, com a criação de serviços de Educação Especial em todas as Secretarias Estaduais de Educação. Em 1974, o Estado de São Paulo contava com 12.904 deficientes estudando em rede pública e, 15.763, em rede privada, entretanto, ao todo significava apenas 10,6\% da população com alguma deficiência.

\footnotetext{
${ }^{9}$ SILVA, Graziela Santos Fernandes da. Deficiência: a inclusão dos cegos nas classes comuns. Disponível em: http://www.educacaoonline.pro.br/art_deficiencia_a_inclusao_do_cego_asp Acesso em: 13 mai.2004.
} 
O terceiro período começou na segunda metade da década de 80 e caminha, hoje, caracterizado pelos movimentos em favor da inclusão na rede pública. Além disso, em 1986, foram criadas SESPE (hoje extinta) e a CORDE (Coordenadoria Nacional para a Integração da Pessoa Portadora de Deficiência); em 1992, com outro nome, SEESP, a Secretaria de Educação Especial foi ativada. Esses órgãos públicos contribuem para a melhora das políticas governamentais em relação aos deficientes.

Como visto, ao longo do tempo, foram se ampliando as variedades de deficiência atendidas educacionalmente. A demanda de deficientes ainda está longe de ser suprida, porém algumas iniciativas institucionais, particulares e governamentais, tiveram grande importância para tal fim.

\subsection{Idéias norteadoras}

Ao se analisar a história da educação especial, percebe-se a forte inclinação para a idéia de que as pessoas portadoras de necessidades especiais devem ser educadas na rede regular, usando as instituições especializadas como suporte técnico e profissional. Documentos internacionais, legislações estrangeiras e nacionais, projetos governamentais do Ministério da Educação insistem na política inclusiva.

Do ponto de vista dos professores, a inclusão é justa, necessária e viável; concordando com o primeiro ponto de vista. Entretanto, eles exigem que determinadas condições sejam atendidas para um bom funcionamento desse projeto ideal.

Não obstante, outros profissionais, inclusive professores, acreditam ser impossível tal inclusão. Segundo eles, as pessoas especiais nunca seriam mais bem atendidas e educadas em rede regular do que nas instituições especializadas, por uma série de motivos.

Há, também, uma idéia muito forte no meio educacional de que o problema da
diversidade humana e cultural tem que ser tratado pela escola, os professores
precisam saber lidar com a diversidade, têm que mudar o currículo etc., e nos
esquecemos de que a diversidade, em boa parte, é uma questão basicamente de
desigualdade social, portanto, ela extrapola o mundo da escola.
(...) Em relação às diversidades e às desigualdades, é muito injusto que políticas
globais de atendimento às diferenças resolvam jogar para as escolas
responsabilidades que são da sociedade como um todo. ${ }^{10}$

$\mathrm{Na}$ vertente do entendimento em epígrafe, várias pessoas pensam que essa política de inclusão poderia causar mais exclusão, discriminação e marginalização, pois exigir que as

\footnotetext{
${ }^{10}$ LIBÂNEO, José Carlos. Igualdade e diversidade: qual proposta de escola incursiva? Educativa, Goiânia, v.5, n. 1, p.135 - 145, jan./jun., 2002. p137 e 138.
} 
pessoas especiais atinjam o mesmo nível que aquelas sem necessidades educacionais específicas é fator de exclusão, já que eles não têm os mesmos pontos de base, de partida. A melhor política inclusiva, então, seria oferecer-lhes cuidados especiais, com educadores qualificados, com possibilidade de atendimento em turmas pequenas, em instituições especializadas.

A inclusão de todas as crianças em um só ambiente, como ideal, é a medida mais perfeita para que todos aprendam a viver juntos; aprendizado que é um dos pilares da educação do século XXI (aprender a conhecer, aprender a fazer, aprender a ser e aprender a viver juntos). No entanto, existem muitas barreiras a serem quebradas e muitos passos, a longo e curto prazos, a serem dados.

\section{PROTEÇÃO DOS PORTADORES DE NECESSIDADES EDUCACIONAIS ESPECIAIS EM ÂMBITO INTERNACIONAL}

Depois de caracterizados e contextualizados os portadores de necessidades educacionais especiais, pode-se entender, agora, como a proteção de seus direitos caminhou no mesmo sentido progressivo. À medida que se abandonou a política social e educacional segregatória dessas pessoas e passou-se a enxergá-las como titulares de direitos e obrigações como qualquer outra, inclusive nos direitos de obter dignidade, cidadania, liberdade, informação e educação; a necessidade de assegurá-los aumentou proporcionalmente. Além disso, "a importância do tema foi emergindo à medida que a própria sociedade descobriu que os portadores de necessidades especiais são educandos, ou seja, etimologicamente, devem ser educados."11

A preocupação nacional e internacionalmente com essas pessoas tornou-se forte após a $2^{\mathrm{a}}$ Guerra Mundial, com o aumento do número de deficientes por conseqüência das mutilações em campo de batalha. Então, a partir desse fato, diversos documentos foram criados para orientar, assegurar e viabilizar os direitos gerais e específicos dos portadores de necessidades especiais; gerando a igualdade material proposta pelo ordenamento jurídico nacional e alienígena.

O direito à educação é a base para qualquer pessoa conquistar outros direitos fundamentais como o direito à cidadania e a liberdade. Por essas razões, todos, sem

\footnotetext{
${ }^{11}$ CARNEIRO, Moaci Alves. LDB fácil: leitura crítico-compreensiva artigo por artigo. 8 ed. Petrópolis: Vozes, 2002. p. 142.
} 
discriminação, possuem o direito de serem ajudados, mais ou menos, conforme sua peculiaridade e necessidade, a desenvolverem suas inteligências, e conseqüentemente alcançarem sua cidadania e liberdade em um Estado Democrático de Direito.

Desse modo, é de extrema importância para um país o estudo internacional de um determinado assunto. Observar quais os caminhos que o mundo escolheu para a educação especial, a partir de estudos e experiências vividas mal ou bem sucedidas, é encurtar caminho para o êxito.

\subsection{Intervenção da ONU (UNESCO)}

No âmbito internacional, a Organização das Nações Unidas (ONU) é a dirigente da garantia dos direitos humanos e promove a paz através de acordos e tratados entre seus países membros. Desde sua formação, ela se preocupa, entre outros, com os marginalizados pela raça, sexo, nacionalidade, idade e deficiência, perante a saúde, segurança, trabalho e educação. Portanto, subdividiu-se para um melhor resultado em todas as áreas, e na educação, a subdivisão redundou na criação de um órgão denominado UNESCO.

A UNESCO foi criada em 16 de novembro de 1945, e sua representação no Brasil foi estabelecida em 19 de junho de 1964, com o intuito de promover a paz e os direitos humanos, baseando-se na solidariedade intelectual e moral da humanidade. Suas atividades situam-se predominantemente nos setores da educação, cultura, ciência, tecnologia, comunicação, informática, meio ambiente, direitos humanos e gestão social. Ela tem o objetivo de intermediar projetos de cooperação técnica firmados com o governo (políticas públicas) e também com a sociedade civil, auxiliando na medida em que seus propósitos estejam em sintonia com as metas da ONU. Seus países membros e associados somam ao todo 192 Estados segundo dados da própria UNESCO.

Na área de proteção aos portadores de necessidades especiais inúmeras foram as ações e documentos promovidos pela UNESCO. “Assim foi que, em 1971, a Assembléia Geral da ONU aprovou, em resolução, a Declaração dos Direitos das Pessoas com Retardo Mental. Em 9 de dezembro de 1975, aprovou ainda a Res. XXX/3.447, consistente na Declaração dos Direitos das Pessoas Deficientes. A seguir, 1981 foi declarado O Ano Internacional das Pessoas Deficientes, o que permitiu acentuar a preocupação mundial com a questão”. ${ }^{12}$ Em, 3

\footnotetext{
${ }^{12}$ MAZZILLI, Hugo Nigro. O Ministério Público e a Pessoa Portadora de Deficiência. Disponível em: < http://www.pgt.mpt.gov.br/publicacoes/pub01.html> Acesso em: 20 jun. 2004.
} 
de dezembro de 1982 proclamou, pela resolução 37/53, a "Década das Nações Unidas para as pessoas com deficiência” No Brasil, com parceria do MEC, a UNESCO realiza programas de capacitação de educadores, apoiou eventos como o Congresso Internacional sobre Superdotação e III Congresso Íbero-Americano de Educação Especial, ambos em 1998, dentre outros.

Os mais importantes documentos internacionais para a educação dos portadores de necessidades educacionais especiais aprovados pelas Nações Unidas são a "Declaração Mundial sobre Educação para Todos”, em 1990, Jointen, na Tailândia, documento reafirmado no ano de 2000, em Dakar, Senegal, pela “Declaração de Dakar” e; a "Declaração de Salamanca”, Espanha, no ano de 1994, o qual versa sobre princípios, política e prática em educação especial. Eles são a fonte direta dos ordenamentos jurídicos mundiais no que tangem à educação especial. Os países membros da UNESCO, devem seguir em suas Cartas Magnas, leis e documentos infra-legais os princípios propostos por aqueles documentos, e seus governantes devem, por meio de suas políticas públicas, respeitar o Estado de Direito e, conseqüentemente, praticar a inclusão social e educacional de todos, sem exceções.

\subsection{Declaração Mundial de Educação para Todos}

Depois da Declaração Universal dos Direitos Humanos, a qual afirmava que "toda pessoa tem direito à educação”, o mundo, no começo da década de 90, observou a necessidade de fazer cumprir esse direito, já que dados estatísticos mostraram a grande quantidade de pessoas sem ao menos a educação básica: mais de 100 milhões de crianças e de 960 milhões de adultos.

Foi nessa realidade, que a “Declaração Mundial de Educação para Todos” no ano de 1990 em Jointen, Tailândia, foi realizada. As necessidades básicas de aprendizagem precisavam ser satisfeitas para que problemas endêmicos do mundo, como a injustiça social, fossem combatidos com o conhecimento. Se as nações seguissem os princípios dessa declaração, o quadro educacional e suas conseqüências seriam fantasticamente melhores.

O principal objetivo dessa declaração é satisfazer as necessidades básicas da aprendizagem de todas as crianças, jovens e adultos. Para tal fim, existem objetivos intermediários que darão base ao primeiro com metas específicas dentro de planos de governo educacionais nacionais e estaduais. Um exemplo seria a definição de categorias prioritárias: pobres, portadores de deficiência. “As necessidade básicas de aprendizagem das pessoas portadoras de deficiência requerem atenção especial. É preciso tomar medidas que garantam a 
igualdade de acesso à educação aos portadores de qualquer tipo de deficiência, como parte integrante do sistema educativo.”13

Observa-se no corpo desse documento, uma atenção especial aos portadores de necessidades especiais e às mulheres, pois sendo a meta principal a educação para todos e tendo esses grupos maiores obstáculos ao acesso a educação, nada mais justo que privilegiálos para lograr no futuro a clamada igualdade material.

Definidos os objetivos, a Declaração dividiu seus planos de ação em níveis nacional, regional e mundial.

No primeiro nível, julgou-se necessário: avaliar necessidades e planejar ações, desenvolver um contexto político favorável, definir políticas para a melhoria da educação básica, aperfeiçoar capacidades gerenciais, analíticas e tecnológicas, mobilizar canais de informação e comunicação, estruturar alianças e mobilizar recursos. A mobilização de recursos estatais deve ser bem estruturada e devidamente cumprida.

\begin{abstract}
Os governos e seus parceiros podem analisar a alocação e uso corrente dos recursos financeiros e outros para a educação e capacitação nos diferentes setores, a fim de determinar se apoio adicional à educação básica pode ser obtido mediante: o incremento da eficácia; a mobilização de fontes adicionais de financiamento, dentro e fora do orçamento público; e a redistribuição dos fundos dos orçamentos de educação e capacitação atuais, levando em conta os critérios de eficácia e eqüidade. Nos países onde a contribuição orçamentária total para a educação é escassa, será necessário estudar a possibilidade de realocar, para a educação básica, certos fundos públicos, anteriormente destinados a outros fins.
\end{abstract}

Avaliar os recursos já destinados ou potencialmente disponíveis para a educação básica, comparando-os com o orçamento previsto para a execução do plano de ação, permite detectar possíveis inadequações que, a longo prazo, podem afetar o calendário das atividades planejadas ou solicitar alternativas diversas de solução. Os países que necessitam de ajuda externa para satisfazer as necessidades básicas de aprendizagem de suas populações podem utilizar a estimativa de recursos e o plano de ação como base para a discussão com seus aliados internacionais, e também para coordenar financiamentos externos. ${ }^{14}$

Já em nível regional (continental, subcontinental e intercontinental), a cooperação entre países de condições ou interesses similares é o que ajuda no objetivo da educação para todos. Muitas vezes, ações em nível nacional não são suficientes, então, o intercâmbio de informações, experiências e competências, além do empreendimento de atividades conjuntas por diversos países acabam sendo essenciais.

\footnotetext{
${ }^{13}$ ONU. UNESCO. Declaração Mundial de Educação para Todos, entre 5 e 9 de março de 1990. Disponível em: $<$ http:// www.unicef.org/brazil/jomtien.htm> Acesso em: 20 jun. 2004.

${ }^{14}$ Ibid.
} 
Finalmente, em nível mundial, há uma necessidade de cooperação, de uma solidariedade internacional perante os países que queiram e precisem de ajuda para desenvolver suas capacidades nacionais em relação à educação proposta pela Declaração. Além disso, a prestação de apoio contínuo e de longo prazo às ações nacionais e regionais e consultas acerca de questões de políticas (canais e fóruns, como a Conferência Internacional de Educação que ocorre de dois em dois anos) são ações prioritárias nesse nível de luta em prol da educação.

Dez anos depois da Declaração Mundial de Educação para Todos, visto que a situação da educação básica melhorou, mas não o suficiente, outra declaração foi formulada para reafirmar e dar continuidade ao objetivo de educação para todos, com vistas no ano de 2015: a declaração de Dakar, Senegal, no ano 2000.

A Avaliação de EPT 2000 demonstra que houve progresso significativo em muitos
países. Mas é inaceitável que no ano 2000 , mais de 113 milhões de crianças
continuem sem acesso ao ensino primário, que 880 milhões de adultos sejam
analfabetos, que a discriminação de gênero continue a permear os sistemas
educacionais e que a qualidade da aprendizagem e da aquisição de valores e
habilidades humanas estejam longe das aspirações e necessidades de indivíduos e
sociedades. Jovens e adultos não têm acesso às habilidades e conhecimentos
necessários para um emprego proveitoso e para participarem plenamente em suas
sociedades. Sem um progresso acelerado na direção de uma educação para todos, as
metas nacionais e internacionais acordadas para a redução da pobreza não serão
alcançadas e serão ampliadas as desigualdades entre nações e dentro das
sociedades. ${ }^{15}$

O compromisso de “educação para todos” é um compromisso inclusive com os portadores de necessidades especiais. Essas declarações demonstram o interesse para que todos, sem exclusão, possam ter a chance de receber um tratamento escolar; mostrando assim, a preocupação internacional com os direitos desses cidadãos.

Além dessas declarações, a que se preocupa direta e especificamente com essas pessoas é a Declaração de Salamanca.

\subsection{Declaração de Salamanca}

A Declaração de Salamanca foi elaborada no ano de 1994, Espanha, pela parceria do governo espanhol e a UNESCO. Ela versa sobre princípios, política e prática em educação

15 ONU. UNESCO. Declaração de Dakar. Disponível em: < http://www.interlegis.gov.br/processo_legislativo/copy_of_20020319150524/20030620161930/2003062311141 5/view> Acesso em: 20 jun. 2004. 
especial, ou seja, estrutura várias ações nacionais e internacionais para que os portadores de necessidades educacionais especiais tenham acesso à educação.

Seu objetivo é informar sobre políticas e guias de ações governamentais, de organizações internacionais ou agências nacionais de auxílio, organizações nãogovernamentais e outras instituições na implementação da Declaração de Salamanca sobre princípios, política e prática em Educação Especial. A Estrutura de Ação baseia-se fortemente na experiência dos países participantes e também nas resoluções, recomendações e publicações do sistema das Nações Unidas e outras organizações inter-governamentais, especialmente o documento "ProcedimentosPadrões na Equalização de Oportunidades para pessoas Portadoras de Deficiência . Tal Estrutura de Ação também leva em consideração as propostas, direções e recomendações originadas dos cinco seminários regionais preparatórios da Conferência Mundial. ${ }^{16}$

Seu princípio central é a educação de modo inclusivo, preferindo a educação em rede regular àquela em instituições especializadas. Esse documento é voltado para o esforço em proporcionar uma educação exclusivamente para portadores de necessidades educacionais especiais e em conseqüência disso, é um instrumento para o cumprimento da Declaração Mundial de Educação para Todos; pois impõe mais esforços nas áreas mais difíceis de se conseguir uma educação de qualidade, como a dessas pessoas.

O princípio que orienta esta Estrutura é o de que escolas deveriam acomodar todas as crianças independentemente de suas condições físicas, intelectuais, sociais, emocionais, lingüísticas ou outras. Aquelas deveriam incluir crianças deficientes e super-dotadas, crianças de rua e que trabalham, crianças de origem remota ou de população nômade, crianças pertencentes a minorias lingüísticas, étnicas ou culturais, e crianças de outros grupos desavantajados ou marginalizados. ${ }^{17}$

A Declaração de Salamanca, baseada nesse princípio serve como guia geral para o planejamento de ação em educação inclusiva, cabendo aos países adaptá-lo às suas peculiaridades.

Como linhas de ação em nível nacional, a Declaração propôs que cada país: reconheça em sua legislação o Princípio de Igualdade de oportunidades para pessoas com necessidades especiais, formule seus arranjos políticos e de financiamento de modo a encorajar e facilitar o desenvolvimento de escolas inclusivas, promova todas as mudanças nas escolas necessárias à inclusão (desde rampas a grades escolares), amplie a informação do povo à respeito da prática inclusiva (conscientização pública), incentive a pesquisa nessa área, treine professores para que atendam com qualidade esse alunado, envolva professores e toda a comunidade através da descentralização e planejamento local, e principalmente mobilize e distribua recursos às

\footnotetext{
${ }^{16}$ Declaração de Salamanca. Op. cit., nota 8

${ }^{17}$ Declaração de Salamanca. Op. cit., nota 8
} 
escolas e a serviços de treinamento de professores competentemente. Esses são algumas das ações indicadas para que ocorra a educação inclusiva.

Já em níveis regional e internacional, a cooperação de organizações governamentais e não-governamentais servirão de apoio ao movimento da inclusão. O planejamento de ações conjuntas, a assistência técnica e tecnológica, o intercâmbio de dados e a troca de informações entre países são exemplos de como as ações nesses níveis são importantes para o escopo final da Declaração.

Dez anos depois da Declaração de Salamanca, relatos de diversos países mostram que houve progresso perante a educação especial, entretanto a resistência à inclusão ainda é muito grande.

Desse modo, apesar de todos os esforços mundiais, o propósito da educação inclusiva ainda precisa de muitos esforços conjuntos para ser concretizado. As duas Declarações apresentadas são as mais importantes na linha da Educação Inclusiva, porém como já dito, há a necessidade de mais contribuições para torná-la efetiva mundialmente.

\section{PROTEÇÃO NORMATIVA NO BRASIL}

No Brasil, a proteção dos direitos dos educandos com necessidades especiais progrediu lentamente. Somente em 1957, essa educação foi assumida no país pelo governo federal e, no ano de 1961, já estava vigorando a primeira Lei de Diretrizes e Bases da Educação Nacional. Nessa lei, foram escritos dois artigos (88 e 89) referentes à educação dos excepcionais, garantindo, dessa forma, o direito à educação das pessoas com necessidades especiais, pelo menos na letra da lei, dentro do sistema geral de ensino, objetivando a integração das pessoas deficientes na comunidade. ${ }^{18}$

A primeira vez em que foram escritos artigos sobre os direitos educacionais dessas pessoas, em uma Carta Magna Nacional brasileira, foi na elaborada em 1967. E, na atual Constituição Federal, a de 1988, há "vários capítulos, artigos e incisos sobre educação, habilitação e reabilitação da pessoa deficiente, além da sua integração à vida comunitária.”19 Em 1990, a lei ${ }^{0}$ 8069/90, Estatuto da Criança e do Adolescente, volta a mencionar os direitos educacionais desses educandos nos artigos (53,inc.I; 54,inc.III). Porém, foi só em

\footnotetext{
${ }^{18}$ CARMO, Sônia Maria do. Um breve panorama do que já foi feito pela educação especial no Brasil e no mundo. Disponível em: < http://www.cidadania.org.br> Acesso em: 20 mai. 2004

${ }^{19}$ Ibid.
} 
1996 que foi criada a atual Lei de Diretrizes e Bases da Educação Nacional, a qual reafirmou a Constituição Federal e dedicou, exclusivamente, um capítulo inteiro, composto por três artigos, para a Educação Especial.

Atualmente, para que essas legislações sejam cumpridas, há o auxílio da Coordenadoria Nacional para Integração da Pessoa Portadora de Deficiência (CORDE) e, dentre outras normas, existem a lei federal 7853/89 e o decreto $n^{0}$ 3298/99, que a regulamenta. Tais normas instituem a tutela jurisdicional de interesses coletivos e difusos dos portadores de necessidades educacionais especiais, disciplinam a atuação do Ministério Público e define crimes, dentre outras providências.

Como exemplo para coerção desses direitos a lei federal citada dispõe, no seu artigo $8^{\circ}$, I que constitui crime recusar, suspender, procrastinar, cancelar ou fazer cessar, sem justa causa, a inscrição de aluno em estabelecimento de ensino de qualquer curso ou grau, público ou privado, por motivos derivados da deficiência que porta.

Após esse panorama legislativo, esmiuçar-se-á o assunto perante a Constituição Federal.

\title{
3.1 A Constituição Federal
}

Garantidos os direitos dos portadores de necessidades educacionais especiais pela Constituição Federal, outras leis complementá-la-ão para que eles sejam realmente aplicados. É o fenômeno da filtragem constitucional e do princípio da supremacia da Constituição federal que vige no neoconstitucionalismo.

\begin{abstract}
A supremacia constitucional, em nível dogmático e positivo, traduz-se em uma superlegalidade formal e material. A superlegalidade formal identifica a Constituição como a fonte primária da produção normativa, ditando competências e procedimentos para a elaboração dos atos normativos inferiores. E a superlegalidade material subordina o conteúdo de toda a atividade normativa estatal à conformidade com os princípios e regras da Constituição. ${ }^{20}$
\end{abstract}

Portanto, cumpre analisar os mandamentos da Constituição Federal nos diversos artigos que protegem os portadores de necessidades especiais, tais como arts.: $3^{\text {o }}$; 23, inc.II; 24, inc.XIV; 37, inc.VII; 70, inc.XXXI; 203, incs. IV e V; 208, inc.III; 227,caput, §1º,II e §20. Entretanto, os que versam sobre educação estão entre o artigo 205 e 214.

\footnotetext{
20 BARROSO, Luís Roberto. Interpretação e aplicação da Constituição: fundamentos de uma dogmática constitucional transformadora. 6. ed. São Paulo: Saraiva, 2004, p.164
} 
“Art.205. A educação, direito de todos e dever do Estado e da família, será promovida e incentivada com a colaboração da sociedade, visando ao pleno desenvolvimento da pessoa, seu preparo para o exercício da cidadania e sua qualificação para o trabalho.”21

Sendo a educação um direito de todos, não há como justificar a exclusão dos portadores de necessidades especiais e, sendo a Educação um dever do Estado e da família, o Estado não pode se esquivar do seu oferecimento formal (escolas), e a família, do dever de matricular a criança. "Direito de todos e dever do Estado constituem-se expressões designativas de direito social a que correspondem às obrigações do Poder Público, materializadas em ações governamentais previamente definidas e priorizadas, reunidas em um conjunto integrado pela busca da mesma finalidade.”22

Além disso, esse artigo demonstra a importância da educação para o futuro da criança com relação ao alcance da cidadania e da dignidade humana, dois dos fundamentos constitucionais, bem como se refere à erradicação da marginalidade que é objetivo da nossa República. Embora essa última relação não seja mencionada no artigo, ela é subentendida "na medida em que a saída da marginalidade pressupõe a aquisição de conhecimento que possibilite condições para a superação das adversidades decorrentes da falta de cumprimento das obrigações ínsitas aos demais direitos fundamentais.”23

Então, o direito à educação remete ao portador de necessidades especiais mais dois direitos maiores e anteriores aos fundamentais e sociais, que são fundamentos constitucionais da República Federativa do Brasil: a cidadania (art. $1^{\circ}$, inc.II) e a dignidade humana (art. $1^{\circ}$, inc.III).

Como princípio fundamental, há uma pretensão constitucional de transformá-lo em um parâmetro objetivo de harmonização dos diversos dispositivos constitucionais, obrigando o intérprete a buscar uma concordância prática entre eles, na qual o valor acolhido no princípio, sem desprezar os demais valores constitucionais, seja efetivamente preservado. ${ }^{24}$

Porém o que se entende por esses princípios?

Em relação à dignidade:

\footnotetext{
${ }^{21}$ BRASIL.Constituição da República Federativa do Brasil: promulgada em 5 de outubro de 1988 . 31 ed. São Paulo: Saraiva, 2003. Art. 205. p. 131

${ }^{22}$ PAULA, Paulo Afonso Garrido de. Educação. Direito e Cidadania p.91-103. In: Cadernos de Direito da Criança e do Adolescente 1. São Paulo: Malheiros, 1995. 208 p. p.94

${ }^{23}$ Ibid., p. 95

${ }^{24}$ MARTINS, Flademir Jerônimo Belinati. Dignidade da pessoa humana: princípio constitucional fundamental. Curitiba: Juruá, 2003. 142 p., p. 124.
} 
(...) vários são os conceitos utilizados pela doutrina nacional, quase todos eminentemente descritivos. Mas, em síntese, concluímos que a dignidade efetivamente constitui qualidade inerente a cada pessoa humana que a faz destinatária do respeito e proteção tanto do Estado, quanto das demais pessoas, impedindo que ela seja alvo não só de quaisquer situações desumanas ou degradantes, como também lhe garantindo o direito de acesso a condições existenciais mínimas. ${ }^{25}$

A dignidade é o núcleo valorativo da Constituição Federal, é seu valor fundante. Sendo um atributo que todo ser humano possui, ela é o núcleo em torno do qual gravitam os direitos fundamentais, como por exemplo, o direito social à educação. Ela está ligada ao mínimo existencial e o Estado deve disponibilizar esse mínimo com ações positivas e negativas.

Já em relação à cidadania, não se pode ater-se somente ao conceito de pessoa que tem o direito de votar e ser votada, nem tampouco resumi-lo ao exercício dos direitos civis, econômicos e sociais pela pessoa humana.

A cidadania reclama atendimento aos interesses protegidos pela lei, porquanto, como direitos fundamentais, são essenciais para o desenvolvimento da pessoa humana e manutenção da própria dignidade. (...) Cidadão é aquele que participa da divisão da riqueza da cidade, da Nação, podendo atender às suas necessidades básicas e vitais, sem as quais não vive, não se desenvolve e nem atualiza suas potencialidades. $^{26}$

Portanto, a educação, como direito e bem fundamental da vida, é um dos atributos da dignidade e também da cidadania, fazendo parte de suas essências. Oferecer educação para os portadores de necessidades especiais, é dar-lhes base para ser um cidadão digno.

Analisando o próximo artigo da Carta Magna do capítulo da educação, verifica-se, em seu primeiro inciso, outro princípio constitucional, o da Igualdade:

“Art.206. O ensino será ministrado com base nos seguintes princípios:

I - igualdade de condições para o acesso e permanência na escola;”27

O constituinte sentiu a necessidade de repetir o assegurado pelo art. $3^{\circ}$, inc. IV, o qual repele qualquer forma de discriminação, e pelo art. $5^{\circ}$, caput, que assegura, como direito fundamental, a igualdade perante a lei. Os direitos fundamentais podem ser entendidos como “direitos básicos da pessoa, como os direitos que constituem a base jurídica de cada pessoa, eles dependem das filosofias políticas, sociais e econômicas e das circunstâncias de cada época e lugar.”28 Dessa forma, a igualdade é defendida como princípio e direito fundamental.

\footnotetext{
${ }^{25}$ MARTINS, Flademir Jerônimo Belinati. Op. cit., p.127, nota 24

${ }^{26}$ PAULA, Paulo Afonso Garrido de. Op. cit. p. 93, nota 22.

${ }^{27}$ CONSTITUIÇÃO FEDERAL. Art. 206 Op. cit. p. 131., nota 21.

${ }^{28}$ MIRANDA, Jorge. Manual de direito constitucional: direitos fundamentais. tomo IV, 2. e d. Coimbra: Coimbra Editora Limitada, 1993, 485 p., p. 09-10.
} 
Deve-se entender que a "igualdade de condições” explicitada pelo art. 206, inc.I, é a igualdade material “Ora, no que diz respeito às pessoas portadoras de deficiência de qualquer natureza, o objetivo da lei é semelhante, quando procura compensar aquele que suporta um tipo de limitação física ou psíquica, ou de qualquer outra natureza, ao conferir-lhe maior proteção.”29

Entretanto, o desrespeito à igualdade formal em prol da material só é permitido se for devidamente justificado. “O certo, porém, é verificar se há justificativa racional, isto é, fundamento lógico, para, à vista do traço desigualador escolhido, conferir o específico tratamento jurídico construído em função da desigualdade proclamada.” 30

Um exemplo de justificativa pode ser pelo objeto em estudo: se, para uma pessoa com deficiência física, há necessidade de rampas por todo o colégio, para que nele possa estudar, essas deverão ser construídas. E por quê? Com o fim de o portador dessa deficiência tenha a mesma possibilidade de entrar e permanecer em uma escola como qualquer outra criança, ele necessita que lhe proporcionem esse "algo a mais”(rampas) para que tenha iguais condições (igualdade material) de estudar, iguais às de um “não deficiente-físico”. Assim, os portadores de necessidades educacionais especiais têm o direito de exigir por lei (igualdade formal) que sejam atendidas suas condições para terem acesso à educação. Então a lei permite privilégios para ser justa perante os desiguais:

\begin{abstract}
A igualdade dos sujeitos na ordenação jurídica, garantida pela Constituição não significa que estes devam ser tratados de maneira idêntica nas normas e em particular nas leis expedidas com base na Constituição. A igualdade assim entendida não é concebível: seria absurdo impor a todos os indivíduos exatamente as mesmas obrigações ou lhes conferir exatamente os mesmos direitos sem fazer distinção alguma entre eles, como, por exemplo, entre crianças e adultos, indivíduos mentalmente sadios e alienados, homens e mulheres. ${ }^{31}$
\end{abstract}

Além da estrita relação com o princípio da igualdade, o art. 206 funciona como instrumento de justiça social, “já que assegura as mais amplas oportunidades educacionais, através da igualdade de condições para o acesso e a permanência na escola”32 e, provavelmente, uma futura e efetiva participação política desses educandos.

Já o art. 208 é mais específico no tratamento da educação especial:

\footnotetext{
${ }^{29}$ MAZZILLI, Hugo Nigro. Op. cit., nota 12

${ }^{30}$ MELLO, Celso Antônio Bandeira de. O Conteúdo Jurídico do Princípio da Igualdade. São Paulo: Malheiros, 1999. 48p., p. 28.

${ }^{31}$ Théorie pure du Droit. Trad. Francesa da 2. Ed. alemã por Ch Einsenmann. Paris: Dalloz, 1962, p.190. Apud. DE MELLO, Celso Antônio Bandeira. O conteúdo jurídico do princípio da igualdade. 3 ed. São Paulo: Malheiros, 1999. 48 p. , p.11

32 BASTOS, Celso Ribeiro; MARTINS, Ives Granda. Comentários à Constituição do Brasil. 8. v. (arts.193 a 232) São Paulo: Saraiva, 1998. 1072 p., p. 426
} 
art. 208. O dever do Estado com a educação será efetivado mediante a garantia de:

III- atendimento educacional especializado aos portadores de deficiência, preferencialmente na rede regular de ensino

$\S 1^{\circ} \mathrm{O}$ acesso ao ensino obrigatório e gratuito é direito público subjetivo

$\S 2^{\circ} \mathrm{O}$ não-oferecimento do ensino obrigatório pelo Poder Público, ou sua oferta irregular, importa responsabilidade da autoridade competente ${ }^{33}$

O inciso III reflete a preocupação do legislador, ao dedicar um inciso à parte para a proteção do direito à educação dos portadores de necessidades educacionais especiais, confirmando o princípio da igualdade material e o fomento de educação para todos, proposta pela Declaração Mundial de Educação para Todos, em Jointen. Entretanto, não obriga o Estado a colocá-los na rede regular, como pregado pela Declaração de Salamanca. O termo empregado, “preferencialmente”, transmite uma idéia de que não são todos os portadores de necessidades que, por gravidade da deficiência, podem freqüentar o ensino regular ou que seria melhor a inclusão nesse tipo de ensino, mas não há como obrigar o Estado a incluí-los, apoiando-se nesse inciso.

Já os parágrafos $1^{\circ}$ e $2^{\circ}$ conferem a esses educandos uma forma de reivindicar seu direito de educação. Por ser um direito público subjetivo, ele é inalienável, é um direito personalíssimo, por ser integrante do direito à vida. Dessa forma, o sujeito desse direito pode exigir, a qualquer momento, prestação jurisdicional, caso ele não esteja lhe sendo atribuído. O não-oferecimento ou oferta irregular do ensino obrigatório, normalmente pelo Poder Executivo, importa em responsabilidade do Estado, podendo ser cobrada.

Existindo oferta irregular dessas ações e serviços por parte do Estado, a força
subordinante do direito social violado conduz à necessidade de prestação
jurisdicional, de modo que a ordem social violada pelo poder público, notadamente
através de seu Poder Executivo, possa ser restaurada pelo Poder Judiciário.(...)
Assim, deflui do direito público subjetivo força subordinante em relação ao Estado
não só no que diz respeito ao cumprimento voluntário das obrigações, mas também
na garantia de acesso ao Judiciário para o suprimento coercitivo das omissões
governamentais. $^{34}$

Já o conteúdo dos artigos 212 e 213 trata da destinação de verbas para a educação, tanto para o ensino regular como para instituições sem fins lucrativos; verbas estas que necessitam de boa administração pelas pessoas jurídicas de direito público interno. Será que o Poder Executivo está gerindo uma boa política pública perante sua responsabilidade para com a educação especial? Urge esclarecer esse questionamento porque a educação, principalmente a especial, depende de uma grande mobilização de verbas no âmbito federal, estadual e

\footnotetext{
${ }^{33}$ CONSTITUIÇÃO FEDERAL. Art. 208. Op. cit. p. 132, nota 21.

${ }^{34}$ PAULA, Paulo Afonso Garrido de. Op. cit. , p. 94, nota 22.
} 
municipal. Se, entretanto, elas não estiverem sendo bem distribuídas e nem bem empregadas, o Estado nunca assegurará o direito à educação fora das letras da lei.

\section{O ESTADO E SUA RESPONSABILIDADE PERANTE A EDUCAÇÃO}

Diante da análise legislativa realizada sobre o tema cumpre saber como o Estado brasileiro pode ser responsabilizado em caso de não cumprimento dos direitos dos educandos também já delimitados a priori.

Para se entender melhor como o Estado brasileiro responde pela Educação Especial, necessita-se tecer considerações preliminares sobre o Estado Democrático de Direito adotado pelo Constituição Federal.

Esse tipo de Estado não é a simples união formal dos conceitos de Estado de Direito e Estado democrático, mas sim uma superação do Estado capitalista para configurar outro que promove a justiça social e que o monismo político das democracias populares socialistas não foram capazes de construir. Contudo, a Constituição de 1988 não anseia uma transição para o socialismo ao adotar o Estado Democrático de Direito, apenas visa a realização social profunda pela prática dos direitos sociais inclusos nela, e por outros instrumentos fundados na cidadania e dignidade humana. ${ }^{35}$

Diante dessas considerações, extrai-se que a educação, como direito social, é um objetivo primordial do Estado Democrático de Direito e deve estar ao alcance de todos. Não há nada mais enriquecedor para a personalidade humana do que a educação. “Quando uma sociedade está mal organizada de tal modo que só promove o bem de uma parte de seus integrantes, é sinal de que ela está mal organizada e afastada dos objetivos que justificam sua existência.”36

Como princípios basilares do Estado Democrático de Direito, o ilustre Gomes Canotilho elenca alguns, totalmente aplicáveis ao Direito brasileiro, dentre eles: o princípio da constitucionalidade; princípio democrático; sistema de direitos fundamentais; princípio da justiça social; princípio da igualdade; princípio da divisão de poderes e da independência do juiz; princípio da legalidade; princípio da segurança jurídica. ${ }^{37}$

\footnotetext{
${ }^{35}$ SILVA, José Afonso da. Curso de direito constitucional positivo. 20 ed. Malheiros: São Paulo, 2002, p. 120

${ }^{36}$ DALLARI, Dalmo de Abreu. Elementos de teoria geral do Estado. 20 ed. São Paulo: Saraiva, 1998. 307p., p. 24

${ }^{37}$ CANOTILHO, J. J. Gomes. Direito constitucional. 5 ed. Coimbra: Almedina, 1991, pp.373 e ss
} 
Assim, sendo a igualdade um de seus princípios e direito fundamental, não há escusas para discriminar os portadores de necessidades especiais e nem para deixá-los à margem da educação formal.

\begin{abstract}
Com efeito, verifica-se que os direitos fundamentais podem ser considerados simultaneamente pressuposto, garantia e instrumento do princípio democrático da autodeterminação do povo por intermédio de cada indivíduo, mediante o reconhecimento do direito de igualdade (perante a lei e de oportunidades), de um espaço de liberdade real, bem como por meio da outorga do direito à participação (com liberdade e igualdade). ${ }^{38}$
\end{abstract}

Ademais, por esse rol de princípios apresentados, principalmente o da legalidade, pode-se dizer que toda pessoa física ou jurídica, pública ou privada, tem sua liberdade cerceada, é passível de direitos e obrigações, e pode sofrer coação, caso desrespeite o Direito nacional. A Constituição Federal não pode ser desrespeitada, nem pelos representantes do Estado, em nenhum âmbito de poder. Mesmo que agentes do Estado tenham elaborado a Constituição, a ela também estão submetidos e, conseqüentemente, podem ser responsabilizados se descumprirem seus preceitos e todas as outras legislações infraconstitucionais.

\begin{abstract}
(...) nenhum órgão, ou agente do Estado, por mais alta que seja a sua hierarquia, detém qualquer poder senão o que advém da Constituição, e o tem de exercer rigorosamente pelo modo nesta definido. Como estatuto do Poder, garantia das liberdades, esta Constituição é, por sua própria natureza, condicionante da validade de todo e qualquer ato que os órgãos estatais emitam, e não pode ser por estes alterada (mas apenas por um poder constituinte, embora dela derivado, que o faça pela forma e nos limites que ela própria traçar). Disto decorre a inexorável conseqüência: a invalidade de todo ato praticado ao arrepio da Constituição. ${ }^{39}$
\end{abstract}

Sendo, então, o poder público submetido ao Direito e, conseqüentemente, à Constituição, ele não pode se esquivar do seu dever de garantir a todos o acesso e permanência nas escolas.

Portanto, constituindo o Brasil um "Estado Democrático de Direito", automaticamente, deduz-se seu compromisso com a educação para todos e a responsabilização objetiva, sendo que “a responsabilidade estatal é simples corolário da submissão do Poder Público ao Direito”. 40

\footnotetext{
${ }^{38}$ SARLET, Ingo Wolfgang. A eficácia dos direitos fundamentais. 2 ed. Porto Alegre: Livraria do Advogado, 2001. 392p., p .64

${ }^{39}$ FERREIRA FILHO, Manoel Gonçalves. Estado de direito e constituição. 2 ed. São Paulo: Saraiva, 1999. 153p. p.04

${ }^{40}$ MELLO, Celso Antônio Bandeira de. Elementos de Direito Administrativo. 3 ed. São Paulo: Malheiros, 1992. 370p. p. 325
} 
“(...) se o Estado é um sujeito de direitos, o Estado é responsável. Ser responsável implica responder por seus atos, ou seja, no caso de haver causado dano a alguém, impõe-selhe o dever de repará-lo.” 41

É preciso aprofundar-se melhor nesta questão de responsabilidade estatal nas relações de ensino, para se entender o grau de comprometimento do Estado com a Educação Especial e, conseqüentemente, a possibilidade de os particulares exigirem seus direitos educacionais.

A palavra responsabilidade advém do verbo latino respondere e da raiz spondeo, que significa, encargo, contraprestação; exprimindo, assim, a necessidade de responder por um determinado fato danoso.

Desse modo, quando o Estado produzir dano a terceiro, terá que responder objetivamente, segundo a teoria atual, reparando o dano. "Tendo causado prejuízo ao administrado, seja pela omissão no cumprimento de um dever, seja pela atuação de um órgão ou de um agente, cabe ao Estado a responsabilidade e o conseqüente dever de reparação.”42

Já no plano das relações de ensino, a responsabilidade civil do Estado estará presente sempre que o serviço público educacional estiver inadequado perante o previsto constitucionalmente e em normas regulamentadoras como a Lei de Diretrizes e Bases, decretos, portarias do MEC e resoluções dos Conselhos de Educação. Resumindo, sempre que não respeitar os princípios de eficiência, da continuidade e da igualdade perante os usuários.

Destarte, baseando-se na teoria da culpa do serviço, existem três pressupostos para a responsabilização no caso de omissão do Poder Público: “a) a atividade administrativa, consistente nos serviços públicos educacionais, da qual poderia derivar a falta de serviço, o mau funcionamento, o vício de qualidade ou um incidente capaz de provocar dano; b) o dano material ou moral; c) a relação de causalidade entre o dano e a atividade administrativa de serviços educacionais."

Assim, qualquer portador de necessidade especial, apto a ingressar no ensino regular, que tiver seu direito de matricular-se tolhido, ou não possuir todo o aparato estrutural e pedagógico determinado em lei para que possa acompanhar as aulas, poderá responsabilizar o Estado objetivamente ou, subjetivamente, em caso de omissão. Se não pôde, ou pôde ineficientemente e sem qualidade, usufruir de seu direito, por ato administrativo, houve, pelo menos, dano moral, e o nexo causal esteve presente.

\footnotetext{
${ }^{41}$ MELLO, Celso Antônio Bandeira de. Op. cit., p. 326, nota 40

42 BARBOSA, Carlos Cezar. Responsabilidade civil do Estado e das instituições privadas nas relações de ensino. Rio de Janeiro: Forense Universitária, 2004. 139p. p. 42

${ }^{43}$ Ibid. p. 80
} 
É inegável a potencialidade de produção de dano que pode originar da falta de serviço educacional. A pessoa apta a ingressar no ensino fundamental, que não tem à sua disposição a oferta de serviço, está deixando de se preparar para o exercício da cidadania e para a vida profissional, e essa situação traduz, pelo menos, a geração de danos morais. ${ }^{44}$

Além disso, partindo da premissa de que os serviços educacionais são essencialmente públicos, o Estado tem a obrigação também de zelar pelo serviço do particular autorizado. Assim, se este o estiver exercendo mal e for acionado por algum administrado, o Estado responderá subsidiariamente, caso o prestador de serviço autorizado não apresente solvência suficiente para reparar os danos causados.

Como último comentário sobre a responsabilidade estatal, pode-se afirmar que o $\S 2^{\circ}$, do artigo 208 da nossa Carta Magna, além de natureza político-administrativa, possui natureza criminal.

\begin{abstract}
A propósito, imaginando que determinado prefeito negue cumprimento ao disposto no art.212, da Constituição Federal, que é secundado pelo art. 69 da Lei n. ${ }^{\circ} 9.394$, de 20 de dezembro de 1996, e diz respeito à obrigatoriedade de aplicação de pelo menos $25 \%$ da receita resultante de impostos na manutenção e desenvolvimento do ensino, terá ele, em tese, praticado o delito previsto no art.1 $1^{\circ}$, incs. III e IV, do Decreto-lei n. ${ }^{\circ}$ 201, de 27 de fevereiro de 1967, sujeitando-se a uma pena de três meses a três anos de detenção. Além disso, a conduta faltosa poderá tipificar ato de improbidade administrativa, capitulado no art. 11, II, da Lei n. ${ }^{\circ}$ 8.429, de 2 de junho de 1992, e punido na forma do art. 12, III, do mesmo diploma. ${ }^{45}$
\end{abstract}

Entendido o dever estatal com a educação e sua responsabilização objetiva, é preciso salientar a importância do Ministério Público e da Defensoria Pública para a proteção dos direitos dos portadores de necessidades especiais e para eventuais necessidades destes para o acionamento do Judiciário, tendo em vista seu direito educacional lesado pelo Poder Público ou particular autorizado.

Devido à dificuldade de acesso ao Judiciário ainda existente no Brasil, tais instituições podem, em nome dos particulares, ingressar com ação civil pública ou mandado de segurança individual ou coletivo, demandando cumprimento de seus direitos coletivos latu sensu ou direitos líquidos e certos, respectivamente.

\title{
CONCLUSÃO
}

Diante do exposto constata-se que a proteção jurídica na educação dos portadores de necessidades especiais vem, com o passar dos anos, ganhando um enorme respaldo normativo.

\footnotetext{
${ }^{44}$ BARBOSA, Carlos Cezar. Op. cit., p. 82, nota 43

${ }^{45}$ BARBOSA, Carlos Cezar. Op. cit. p. 81-82, nota 43
} 
A primeira vitória veio com progresso na sua própria nomenclatura, conferindo maior dignidade a essas pessoas. Termos como anormais ou excepcionais devem ser abandonados.

Outra grande conquista foi a adoção do ensino inclusivo, como objetivo da educação. Esse objetivo encontra-se fundamentado em documentos mundiais e normas internas brasileiras. A Constituição Federal, especialmente, balizou regras e princípios que obrigam o Estado a cumpri-lo, sob pena de responsabilização objetiva.

Desse modo, depreende-se que, ao menos normativamente, hoje, os portadores de necessidades educacionais especiais possuem satisfatória proteção jurídica.

Porém, o atual desafio é o cumprimento da letra da lei pelo Poder Executivo.

Apesar de o Estado pregar uma política inclusiva, os censos escolares promovidos pelo MEC/INEP mostram que ainda há um predomínio das escolas especiais; urge a implementação de políticas públicas articuladas e contínuas para a reversão desse quadro.

As políticas públicas poderiam propor planos mais efetivos e menos eleitoreiros e assistencialistas tentando conferir maior continuidade e devido cumprimento aos planos e financiamento. Atualmente, o que ocorre é que a cada troca de Presidente, de Ministros e Governadores, os planos são trocados para terem a própria marca. Essa descontinuidade de planos, principalmente os que tangem sobre o financiamento da educação, impede um resultado mais eficiente. No ano de 2004, o Ministro da Educação, Cristovam Buarque, foi substituído pelo advogado Tarso Genro; o Fundo de Financiamento - FUNDEF - foi substituído pelo FUNDEB; as instituições especializadas pararam de receber verbas do FUNDEF e, agora, recebem do FNDE. Tudo isso, em um curto período de tempo, não aumentando essa lista com mudanças dos anos anteriores.

Se a descontinuidade não bastasse, o desrespeito aos Fundos também acontece: tanto em não fazer os reajustes definidos em lei como em desviar verbas para outros fins diferentes dos da educação, sendo lícitos ou ílicitos. Torna-se necessário um mecanismo forte de fiscalização dos repasses de verbas, em que toda a sociedade civil deve estar envolvida. Os Conselhos Fiscalizadores já existentes silenciam verdadeiras atrocidades ao dinheiro público.

Complementando, deveria-se propor melhor articulação entre os membros do executivo: os níveis Federal, Estadual e Municipal; entre as escolas públicas e privadas; entre os diversos níveis e modalidades de ensino; e entre as diversas secretarias (de assistência social, da cidadania, da saúde, a educação, do transporte...) para melhor continuidade do ensino. 
Ressalta-se, por fim, que o neoconstitucionalismo vem conferindo maior força ao Poder Judiciário, para alcançar os fins do pós-positivismo. Assim, a jurisprudência caminha no sentido de permitir cada vez mais sua intervenção no Poder Executivo, inclusive quanto às políticas públicas. Esta seria uma boa forma de coerção em prol da educação inclusiva.

\section{REFERÊNCIAS}

BARBOSA, Carlos Cezar. Responsabilidade civil do Estado e das instituições privadas nas relações de ensino. Rio de Janeiro: Forense Universitária, 2004. 139p.

BARROSO, Luís Roberto. Interpretação e aplicação da Constituição: fundamentos de uma dogmática constitucional transformadora. 6. ed. São Paulo: Saraiva, 2004.

BASAGLIA, Franco. O homem no pelourinho. Revista Educação e Sociedade- CEDES. n 23 São Paulo: CortezCentro de estudos educação e sociedade, 1986.

BASTOS, Celso Ribeiro; MARTINS, Ives Granda. Comentários à Constituição do Brasil. 8. v. (arts.193 a 232) São Paulo: Saraiva, 1998. 1072 p.

BRASIL.Constituição da República Federativa do Brasil: promulgada em 5 de outubro de 1988. 31 ed. São Paulo: Saraiva, 2003. Art. 205.

Lei $n^{\circ}$ 8069, de 13 de julho de 1990. Dispõe sobre o Estatuto da Criança e do Adolescente Disponível em: <http:// www.educacaoonline.pro.br>. Acesso em: 30 mar. 2004.

, Lei n 9394, de 20 de dezembro de 1996. Estabelece as Diretrizes e Bases da Educação Nacional. Disponível em: <http:// www.educacaoonline.pro.br>. Acesso em: 30 mar. 2004.

CANGUILHEM, Georges. O normal e o patológico. 2. ed. Rio de Janeiro: Forense - Universitária, 1982.

CANOTILHO, José Joaquim Gomes. Direito constitucional. 5 ed. Coimbra: Almedina, 1991,

CARMO, Sônia Maria do. Um breve panorama do que já foi feito pela educação especial no Brasil e no mundo. Disponível em: <http://www.cidadania.org.br> Acesso em: 20 mai. 2004

CARNEIRO, Moaci Alves. LDB fácil: leitura crítico-compreensiva artigo por artigo. 8 ed. Petrópolis: Vozes, 2002.

DALLARI, Dalmo de Abreu. Elementos de teoria geral do Estado. 20 ed. São Paulo: Saraiva, 1998. 307p

DEL MASSO, M. C. S. Orientação para o trabalho: uma proposta de adaptação curricular para alunos com deficiência mental. Tese (doutorado)- Universidade de São Paulo. São Paulo, 2000.

DURKHEIN, Émile. As regras do método sociológico. 2. ed. São Paulo: Abril Cultural, 1983.

FERREIRA FILHO, Manoel Gonçalves. Estado de direito e constituição. 2 ed. São Paulo: Saraiva, 1999. 153p.

LIBÂNEO, José Carlos. Igualdade e diversidade: qual proposta de escola incursiva? Educativa, Goiânia, v.5, n. 1, p.135 - 145, jan./jun., 2002.

MARTINS, Flademir Jerônimo Belinati. Dignidade da pessoa humana: princípio constitucional fundamental. Curitiba: Juruá, 2003. 142 p. 
MAZZILLI, Hugo Nigro. O Ministério Público e a Pessoa Portadora de Deficiência. Disponível em: < http://www.pgt.mpt.gov.br/publicacoes/pub01.html> Acesso em: 20 jun. 2004.

MELLO, Celso Antônio Bandeira de. Elementos de Direito Administrativo. 3 ed. São Paulo: Malheiros, 1992. 370p.

. O Conteúdo Jurídico do Princípio da Igualdade. São Paulo: Malheiros, 1999. 48p

MIRANDA, Jorge. Manual de direito constitucional: direitos fundamentais. tomo IV, 2. e d. Coimbra: Coimbra Editora Limitada, 1993, 485 p.

ONU. UNESCO. Declaração de Dakar. Disponível em: <

http://www.interlegis.gov.br/processo_legislativo/copy_of_20020319150524/20030620161930/2003062311141 5/view> Acesso em: 20 jun. 2004.

Declaração de Salamanca, entre 7 e 10 de junho de 1994. Sobre princípios, política e prática em educação especial. Disponível em: <http:// www.educacaoonline.pro.br>. Acesso em: 02 abr. 2004.

. Declaração Mundial de Educação para Todos, entre 5 e 9 de março de 1990. Disponível em: <http:// www.unicef.org/brazil/jomtien.htm> Acesso em: 20 jun. 2004.

PAULA, Paulo Afonso Garrido de. Educação. Direito e Cidadania p.91-103. In: Cadernos de Direito da Criança e do Adolescente 1. São Paulo: Malheiros, 1995. 208 p.

SARLET, Ingo Wolfgang. A eficácia dos direitos fundamentais. 2 ed. Porto Alegre: Livraria do Advogado, 2001. 392p.

SILVA, Graziela Santos Fernandes da. Deficiência: a inclusão dos cegos nas classes comuns. Disponível em: http://www.educacaoonline.pro.br/art_deficiencia_a_inclusao_do_cego_asp Acesso em: 13 mai.2004.

SILVA, José Afonso da. Curso de direito constitucional positivo. 20 ed. Malheiros: São Paulo, 2002. 